\title{
LA RESPONSABILIDAD CIVIL EN LA NUEVA LEY DE ORDENACION DE LA EDIFICACION (38/1999, DE 5 DE NOVIEMBRE)
}

\author{
José Manuel Fernández Hierro
}

\section{La anterior regulación}

La regulación que hasta la fecha existía en materia de responsabilidad en la construcción venía fundamentalmente - aunque no de manera exclusiva- determinada por el artículo 1.591 del Código Civil. Tal regulación no es única de nuestro ordenamiento jurídico, puesto que la mayoría de los ordenamientos continentales — como el francés con el artículo 1.792 - han tenido orientaciones similares.

El artículo 1.591 del Código Civil establecía, como es sabido, una responsabilidad del constructor y el arquitecto por los vicios de la edificación que se evidenciaran durante el denominado período de garantía decenal, vicios que, en principio, eran imputables al constructor cuando se tratara de defectos de edificación y al arquitecto cuando los defectos fueran del suelo o de la dirección; y responsabilidad que el Tribunal Supremo ha extendido a los aparejadores y a los promotores mediante una amplia jurisprudencia, habiendo señalado también que cuando no se pudiera determinar la parte de responsabilidad de cada interviniente en la construcción la responsabilidad sería solidaria.

La Ley de Ordenación de la Edificación contempla un nuevo régimen con una serie de particularidades y novedades importantes, pero también con una numerosa serie de interrogantes sobre su ulterior aplicación ${ }^{1}$.

\footnotetext{
${ }^{1}$ Para un análisis comparativo de la situación legal anterior y de la derivada de la nueva Ley vease MEZQuita GARCía Granero: «El artículo 1.591 C.C. ante la Ley de Ordenación de la edificación» en Aranzadi Civil, 1999-III, pág. 2301 y ss.
} 
La Ley tiene una serie de novedades como son la definición de los distintos agentes que intervienen en la edificación, enumerados en el capítulo III de la Ley; también se exige para el constructor una titulación o capacitación profesional, aun cuando curiosamente no se dice cuál es, ya que no hay ningún título específico de constructor (y también cabría preguntarse, si existe un proyectista, un arquitecto director y un director de la ejecución de la obra ${ }^{2}$, ¿para qué quiere tener título el constructor?).

$\mathrm{Y}$ algo parecido sucede con el Jefe de obra, que asumirá la representación técnica del constructor en la obra y que deberá tener una capacitación que no se dice cuál es.

También la Ley, por primera vez en nuestro ordenamiento jurídico, se ocupa de otras entidades como los laboratorios de control de calidad en la edificación.

Vamos a tratar de desarrollar esquemáticamente el nuevo régimen legal, si bien aclarando que en este artículo me voy a limitar a los aspectos del mismo que hacen referencia a la responsabilidad civil, omitiendo el restante contenido de la Ley.

\section{Culpa exigible}

La Ley parece adaptar un principio de responsabilidad objetiva en su artículo 17.8 cuando señala que «las responsabilidades por daños no serán exigibles a los agentes que intervengan en el proceso de la edificación, si se prueba que aquéllos fueron ocasionados por caso fortuito, fuerza mayor, acto de tercero o por el propio perjudicado por el daño». Sin embargo y en el fondo tal apreciación legal no es sino la presunción de culpa o la inversión de la carga de la prueba, que tanto la doc-

2 El artículo 13.1 de la Ley señala:

«El director de la ejecución de la obra es el agente que, formando parte de la dirección facultativa, asume la función técnica de dirigir la ejecución material de la obra y de controlar cualitativa y cuantitativamente la construcción y la calidad de lo edificado».

Para GonzÁlez Pérez (Comentarios a la Ley de Ordenación de la Edificación, Madrid 2000, pág. 364) viene a regir las mismas normas sobre titulación académica y profesional habilitante que para el director de la obra y, además, pueden ser ambas la misma persona física. También González Poveda («Comentarios del artículo 1.591 del Código Civil» en Comentarios al Código Civil, Barcelona 2000, t. 7, pág. 639) sostiene la compatibilidad de ambas funciones en una sola persona; y para CORDERO LOBATO («Comentario al artículo 13 LOE» en Comentarios a la Ley de Ordenación de la Edificación, Pamplona 2000, pág. 252) el director de obra «puede ser indistintamente un Arquitecto, un Arquitecto técnico, un Ingeniero o un Ingeniero técnico». 
trina $^{3}$ como la jurisprudencia ${ }^{4}$ habían reconocido, de manera reiterada, que estaba contenida en el artículo 1.591 del Código Civil.

\section{Plazos de garantía}

La Ley contiene una novedad al establecer distintos plazos de garantía en función de la gravedad de los daños o vicios causados (como se hizo anteriormente en Francia por la Ley 78-12 de 4 de enero de 1978 que modificó el artículo 1.794.1 del Código Civil, al revés de lo que hasta ahora sucedía con la aplicación del artículo 1.591 del Código Civil.

Tales plazos vienen fijados en el artículo 17.1 de la Ley que señala:

«1. Sin perjuicio de sus responsabilidades contractuales, las personas físicas o jurídicas que intervienen en el proceso de la edificación responderán frente a los propietarios y los terceros adquirentes de los edificios o parte de los mismos, en el caso de que sean objeto de división, de los siguientes daños materiales ocasionados en el edificio dentro de los plazos indicados, contados desde la fecha de recepción de la obra, sin reservas o desde la subsanación de éstas:

a) Durante diez años, de los daños materiales causados en el edificio por vicios o defectos que afecten a la cimentación, los soportes, las vigas, los forjados, los muros de carga u otros elementos estructurales, y que comprometan directamente la resistencia mecánica y la estabilidad del edificio.

b) Durante tres años, de los daños materiales causados en el edificio por vicios o defectos de los elementos constructivos o de las instalaciones que ocasionen el incumplimiento de los requisitos de habitabilidad del apartado 1, letra c) del artículo 3.

El constructor también responderá de los daños materiales por vicios o defectos de ejecución que afecten a elementos de terminación o acabado de las obras dentro del plazo de un año».

3 CAdarso Palau, La responsabilidad decenal de arquitectos y constructores, Madrid 1976, pp. 171 y ss.; FERNÁNDEZ COSTALES, El contrato de arquitecto en la edificación, Madrid 1977, p. 375; FERNÁNDEZ HIERRO, La responsabilidad civil por vicios de construcción, Bilbao, 1976, pp. 93 y ss.; GARCÍA CANTERO, La responsabilidad por ruina de los edificios en el artículo 1.591 del Código Civil en ADC 1963, p. 1.105; Herrera Catena, La responsabilidad en la construcción, vol 1l, Granada 1977, pp. 124 y ss.; Mucius Scaevola, Código Civil, T. XXIV, 2. ${ }^{a}$ parte, Madrid 1915, p. 99; SANTOS BRIZ, La responsabilidad civil, Madrid 1970, p. 562 y ZorRILla RuIZ, en Derecho Civil de Carbonnier, Barcelona 1971, t. II, vol. III, p. 20.

${ }^{4}$ Sentencias de 31 de enero de 1985, Ar. 223, y 22 de abril de 1988, Ar. 327, entre otras. Así lo reconoce MezQuita García Granero (obra citada, pág. 45). 
Como puede verse se establecen fundamentalmente tres plazos — que como subraya Rodríguez Achutegui ${ }^{5}$ - uno de diez años (para vicios graves) otro de tres años (para defectos que ocasionen el incumplimiento de los requisitos de habitabilidad) y un tercero de un año (de vicios o defectos de ejecución que afecten a elementos de terminación o acabado), plazos mucho más cortos que los hasta ahora existentes.

Los tres supuestos se inspiran claramente en la Ley francesa de 4 de enero de 1978, si bien el segundo de los plazos se aumenta de los dos años que preveía la Ley francesa a los tres.

Para que se pueda exigir la garantía en el plazo de diez años, como hasta ahora, hace falta que los defectos afecten a la cimentación, soporte, vigas, forjados, muro de carga u otros elementos estructurales, con lo que todo lo que no afecte a la estructura del edificio queda excluido de la garantía decenal - por llamarla en los mismos términos que hasta ahora se la conocía-. Pero no solamente se necesita tal requisito, sino que comprometan directamente la resistencia mecánica y la estabilidad del edificio (notemos que el precepto legal que emplea por dos veces el vocablo «y»), con lo cual en una interpretación literal para que la garantía decenal pudiera exigirse haría falta:

1. ${ }^{\circ}$ Que los daños afecten a cimentación, soporte, vigas, forjados, muros de carga u otros elementos estructurales.

2..$^{\circ}$ Que comprometan directamente la resistencia mecánica.

3..$^{\circ}$ Que también comprometan la estabilidad del edificio.

4. ${ }^{\circ}$ ) Que sean daños materiales. La nueva Ley así lo exige la cual parece significar que los daños no materiales son excluidos de su ámbito.

Tal cúmulo de circunstancias será difícil que se produzca en la práctica y por eso parece debe propugnarse que la exigencia de los mencionados requisitos no debe ser acumulativa sino disyuntiva, y tal interpretación se refuerza aún más cuando se trata de los requisitos contenidos en los números $2 .^{\circ}$ y $3 .^{\circ}$.

En cualquier caso, aun entendiéndolo así, gran parte de los vicios o defectos constructivos que hasta ahora podían exigirse durante diez años desaparecen de la garantía, al menos más allá de los dos años que recoge el artículo 17.1.b).

Para que durante el plazo de tres años pueda exigirse responsabilidad por vicios constructivos es menester que tales vicios o defectos

5 «Ley de Ordenación de la Edificación: Responsabilidad, Garantías y Asesoramiento» en Revista del I. Colegio de Abogados del Señorío de Vizcaya, Enero-marzo 1999, págs. 25 y ss. 
ocasionen el incumplimiento de los requisitos de habitabilidad. Tales requisitos vienen determinados en el artículo 3.1.c):

«1. Con el fin de garantizar la seguridad de las personas, el bienestar de la sociedad y la protección del medio ambiente, los edificios deberán proyectarse, construirse, mantenerse y conservarse de tal forma que se satisfagan los requisitos básicos siguientes:

[...]

c) Relativos a la habitabilidad:

c.1.) Higiene, salud y protección del medio ambiente, de tal forma que se alcancen condiciones aceptables de salubridad y estanqueidad en el ambiente interior del edificio y que éste no deteriore el medio ambiente en su entorno inmediato, garantizando una adecuada gestión de toda clase de residuos.

c.2.) Protección contra el ruido, de tal forma que el ruido percibido no ponga en peligro la salud de las personas y les permita realizar satisfactoriamente sus actividades.

c.3.) Ahorro de energía y aislamiento térmico, de tal forma que se consigna un uso racional de la energía necesaria para la adecuada utilización del edificio.

c.4.) Otros aspectos funcionales de los elementos constructivos o de las instalaciones que permitan un uso satisfactorio del edificio».

El artículo 3.1.c) es todo un mosaico de indeterminación e inseguridad jurídica. Así ¿qué es necesario para que el edificio no deteriore el medio ambiente en su entorno inmediato? Y ¿cuáles son las condiciones aceptables de salubridad y estanqueidad?; o hablando de ahorro de energía ¿hasta dónde debe de llegar el uso racional de la energía necesaria para la adecuada utilización del edificio?

Pero donde culmina esta imprecisión es en el apartado c.4) cuando se señala como requisitos de la estabilidad «otros aspectos funcionales de los elementos constructivos o de las instalaciones que permitan un uso satisfactorio del edificio».

Que la Ley exija responsabilidad para algo tan vago, impreciso y subjetivo, como la posibilidad de hacer un uso satisfactorio del edificio, parece un chiste, si no fuera un despropósito.

En cambio los defectos materiales que hasta ahora en la mayoría de los casos - salvo las pequeñas imperfecciones corrientes en palabras de la jurisprudencia - eran exigidos en el plazo de diez años, desde la vigencia de la nueva Ley sólo podrán exigirse durante un año, con la particularidad además de que los técnicos en principio quedan descar- 
gados de tal responsabilidad, que recaerá solamente en el constructor además de la responsabilidad, en su caso, solidaria del promotor ${ }^{6}$.

La nueva Ley muestra un ámbito objetivo de aplicación, en cuanto a los edificios objeto de su garantía, amplio y en consonancia con el criterio que, interpretando el artículo 1.591 del Código Civil, había tenido la jurisprudencia, la cual incluso había aplicado la garantía decenal a la construcción de buques ${ }^{7}$, extendiéndola también a las obras de reparación ${ }^{8}$.

El ámbito de aplicación de la nueva Ley en cuanto a la consideración de edificios viene determinado por el artículo 2.2 de la misma que indica:

«Tendrán la consideración de edificación a los efectos de lo dispuesto en esta Ley, y requerirán un proyecto según lo establecido en el artículo 4, las siguientes obras:

a) Obras de edificación de nueva construcción, excepto aquellas construcciones de escasa entidad constructiva y sencillez técnica que no tengan, de forma eventual o permanente, carácter residencial ni público y se desarrollen en una sola planta.

b) Obras de ampliación, modificación, reforma o rehabilitación que alteren la configuración arquitectónica de los edificios, entendiendo por tales las que tengan carácter de intervención total o las parciales que produzcan una variación esencial de la composición general exterior, la volumetría, o el conjunto del sistema estructural, o tengan por objeto cambiar los usos característicos del edificio.

c) Obras que tengan el carácter de intervención total en edificaciones catalogadas o que dispongan de algún tipo de protección de carácter ambiental o histórico-artístico, regulada a través de norma legal o documento urbanístico y aquellas otras de carácter parcial que afecten a los elementos o partes objeto de protección».

Y de acuerdo con el número 3 del mismo se consideran comprendidas en la edificación sus instalaciones fijas y el equipamiento propio, así como los elementos de urbanización que permanezcan adscritos al edificio.

En cambio, por imperativo de la disposición adicional segunda, la garantía por daños materiales a los que se refiere el apartado 1 del artículo 19 de la Ley se limita a edificios destinados a vivienda (al menos hasta que en el futuro se acuerde su extensión a otro tipo de edificios),

6 Contra la tesis contenida en la nueva Ley pueden citarse muchas sentencias. Véase, por ejemplo, la sentencia de 12 de marzo de 1985, Ar. 1.156 en que la ruina se debe al empleo de malos materiales.

7 Sentencia de 18 de enero de 1972, Ar. 745.

8 Sentencias de 12 de noviembre de 1970, Ar. 4.752; 10 de junio de 1985, Ar. 305 y 22 de septiembre de 1986, Ar. 4.781. 
con lo cual todo lo anterior queda considerablemente mermado al faltar para los otros edificios la garantía que es el fundamento de la responsabilidad civil.

Por otra parte, de acuerdo con la disposición adicional segunda-uno la garantía que es obligatoria a partir de la entrada en vigor de la Ley es la garantía contra los daños materiales a los que se refiere el apartado 1.c) del artículo 19 de la Ley, mientras que quedan sin seguro hasta que mediante Real Decreto se acuerde su obligación los daños previstos en los apartados a) y b) del referido artículo 19.

En definitiva, que sólo los vicios graves que comprometan la estructura, la cimentación, soportes, vigas, forjados, muros de cargas u otros elementos estructurales, van a tener seguro obligatorio y no los otros, que quedan claramente desprotegidos por un triple motivo: por reducirse el plazo de garantía, por reducirse igualmente en muchos casos las personas responsables y finalmente por no estar cubiertos por ningún tipo de seguro.

En otro lugar ${ }^{9}$ manifesté que, en mi opinión, los plazos en que se podía exigir responsabilidad en la construcción no sólo eran excesivamente largos, sino que además suponían un agravio comparativo para los técnicos que intervenían en la construcción en relación a otras actividades y profesiones. Ahora bien, la nueva Ley se pasa al extremo opuesto creando, para los vicios que no afecten a las partes estructurales y fundamentales del edifico, una garantía excesivamente breve y exigua.

\section{Personas responsables}

Las personas responsables se enumeran por el artículo 17.3 de la Ley; y de acuerdo con el artículo 17.3 y aunque éste no lo dice, parece que en principio, y cuando se puede individualizar la causa del vicio o de los daños, responderá solamente el culpable.

Cuando no pueda determinarse quién es el culpable o no se pueda precisar el grado de intervención de cada interviniente, la responsabilidad se exigirá solidariamente, como hasta ahora se venía haciendo con la conocida expresión de «café para todos» ${ }^{10}$. Ahora bien, el ar-

9 Responsabilidad profesional, falta de tratamiento unívoco en «Estudios de Deusto» vol. $45 / 2$, pp. 163 y ss.

10 Así lo determina una constante jurisprudencia del Tribunal Supremo entre la que se puede citar las sentencias de 5 de mayo de 1961, Ar. 2.310, 17 de mayo de 1967, Ar. 2.423; 26 de noviembre de 1984, Ar. 5.659; 2 de diciembre de 1994, Ar. 9.394 y 14 de julio de 1995, Ar. 6.008 . 
tículo 17.3 plantea la responsabilidad solidaria del promotor con los demás agentes en los daños materiales causados por vicios o defectos de construcción; por ello cabe preguntarse ¿por qué se extiende la responsabilidad solidaria al promotor y no a los otros agentes que intervienen en la edificación?

También cabe interrogarse sobre qué quiere decir daños materiales ${ }^{11}$ ocasionados por defecto de construcción ¿se quiere ligar tal expresión con la responsabilidad del constructor, cuando también se alude a daños materiales por vicios o defectos de ejecución? Si quiere hacerse así la expresión no ha sido clara ni acertada, y si por otra parte se quiere limitar la responsabilidad en la nueva Ley a los daños exclusivamente materiales en contraposición a daños personales, aparte de que la expresión empleada por la Ley sigue sin ser feliz, no se encuentra ningún motivo en justicia, ni en técnica jurídica, ni con otro fundamento para eliminar, por ejemplo, los daños personales que hubiera tenido un ocupante del edificio como consecuencia de las lesiones provocadas por su derrumbe parcial del inmueble.

Y no solamente nos encontraríamos con tal interrogante, sino con el límite impreciso del concepto de daños materiales: así por ejemplo, si los ocupantes de una casa tienen que salir de la misma por la gravedad de su estado, que amenaza ruina, ¿los costos que origine su estancia en un hotel o en otra casa, son daños materiales? Aunque la eliminación

11 El requisito de que los daños sean materiales es subrayado por GonZÁlEz PovedA, obra citada, pág. 633. Y RodRíGUEZ ACHÚTEGUI opina que:

«Una leve inclinación, la grieta en un fojado, una fisura en la cubierta, si se han consolidado y no afectan a la estabilidad ni comprometen la resistencia mecánica del inmueble, pese a constituir un afeamiento estético, no darán lugar a ningún tipo de responsabilidad de los agentes de la construcción. El párrafo tercero de la Exposición de Motivos de la LOE, de manera muy gráfica, habla de "seguridad estructural" del edificio. Ha de existir una auténtica ruina del inmueble, pues, al verse comprometidas características arquitectónicas tan esenciales, el inmueble, o parte de él, queda inservible para atender su finalidad» (obra citada, pág. 33).

GoNZÁLEZ PÉREZ (obra citada, págs. 465 y sigs.) señala «que la LOE no sólo ha limitado la presponsabilidad decenal del artículo 1.591, Código Civil, respecto de los elementos a los que han de afectar los defectos o vicios, sino también en orden a la naturaleza de éstos»; y tras analizar cómo la jurisprudencia del Tribunal Supremo anterior a la LOE había reconocido un concepto sumamente amplio de ruina, concluye opinando que «ya no será posible exigir responsabilidad por daños que aparezcan después de tres años desde la recepción de la obra por humedades, filtraciones, desprendimiento de falsos techos, exfoliación de ladrillos, ruptura de tuberías... y tantos otros que, incidiendo en la habitabilidad, no lleguen a comprometer directamente la resistencia mecánica y la estabilidad del edificio». Y también subraya que la Ley sólo comprende «los daños materiales causados en el edificio» CORDERO LOBATO («Comentario al artículo 17 LOE» en Comentarios a la Ley de Ordenación de la Edificación dirigidos por CARRASCO PEREDA, citados, pág. 343). 
de tales daños del catálogo de los indemnizables, parece teóricamente inadmisible, sin embargo, y, como puede verse, la expresión legal también se presta a un sin número de problemas y de controversia?

Pero el interrogante más grave surge al plantearse si el artículo 17.3 puede entrar en colisión con el 17.1. Imaginémonos que unos daños materiales de ejecución de una obra obedecen a un proyecto indebidamente diseñado por el arquitecto. ¿Es exigible la responsabilidad sólo al constructor al tratarse de daños materiales por defectos de ejecución?, o ¿sería de acuerdo con el 17.3 responsable el arquitecto? La respuesta con el texto de la Ley no es totalmente clara, pero la lógica me lleva a propugnar las posibles responsabilidades de los técnicos en esta hipótesis, ya que si el defecto, aunque no ataña a los elementos estructurales, ni comprometa la resistencia mecánica, ni la estabilidad del edificio, es de proyecto, no parece lógico ni justo exigir responsabilidad al constructor que se ha limitado a seguir las instrucciones del arquitecto, máxime cuando en tales casos no sería defecto de ejecución. Por otro lado si no se exige la del constructor porque no es el responsable, ni la del promotor, porque es solidario con el anterior, no podría exigirse responsabilidad a nadie por un claro error de proyecto que comprometiera a la ejecución material del inmueble, hipótesis que encuentro absolutamente inaceptable.

\section{Prescripción}

La jurisprudencia ${ }^{12}$, siguiendo las orientaciones doctrinales ${ }^{13}$, había entendido que habría que distinguir el plazo de garantía y el plazo de prescripción y que el plazo de prescripción de las acciones que nacían del artículo 1.591 del Código Civil, eran de quince años, siempre que el vicio ruinógeno se evidenciara dentro de los diez de garantía dece-

12 Sentencias de 11 de octubre de 1974, Ar. 3.798; 6 de marzo de 1990, Ar. 1.672, 16 de octubre de 1991, Ar. 7.449; 1 de octubre de 1992, Ar. 7.616; 6 de abril de 1994, Ar. 2.940 y 7 de febrero de 1995, Ar. 3.130.

13 Del Arco y Pons, Derecho de la construcción, Madrid 1980, p. 362; FernándeZ HierRo, La responsabilidad civil..., obra citada, p. 148; FERNÁNDEZ Costales, obra citada, pp. 144 y ss.; GÓMEZ DE LA ESCALERA, La responsabilidad civil de los promotores, constructores y técnicos por los defectos de construcción (Estudio del artículo 1.591 del Código Civil y su problemática actual), Barcelona 1990, pp. 210 y ss.; HERRERA CATENA, obra citada, vol. II, p. 16; RuBio SAN Román, La responsabilidad civil en la construcción, Madrid 1987, p. 198, y SÁNCHEZ CALERo, El contrato de obra, su cumplimiento, Madrid 1978, pp. 121 y ss.

En cambio la tesis del plazo único sin distinción entre período de garantía y plazo de prescripción es la dominante en la doctrina y la jurisprudencia francesas desde la decisión de las Cámaras reunidas de 2 de agosto de 1882 (D.P. 83.I.5) y la ha mantenido en nuestro derecho TRAVIESES, «Contrato de arrendamiento», en Revista de Derecho Privado, 1991, pp. 34 y ss. 
nal, con lo cual en la práctica se podía estar hablando de casi veinticinco años.

La nueva Ley acorta notablemente los plazos de prescripción, introduciendo el infrecuente en nuestro ordenamiento jurídico de dos años en su artículo 18, que señala:

«1. Las acciones para exigir la responsabilidad prevista en el artículo anterior por daños materiales dimanantes de los vicios o defectos, prescribirán en el plazo de dos años, a contar desde que se produzcan dichos daños, sin perjuicio de las acciones que puedan subsistir para exigir responsabilidades por incumplimiento contractual.

2. La acción de repetición que pudiese corresponder a cualquiera de los agentes que intervienen en el proceso de edificación contra los demás, o a los aseguradores contra ellos, prescribirá en el plazo de dos años desde la firmeza de la resolución judicial que condene al responsable a indemnizar los daños, o a partir de la fecha en la que se hubiera procedido a la indemnización de forma extrajudicial».

La Ley -que sigue insistiendo en esa expresión de daños materiales que no se sabe exactamente por qué la emplea-, señala un corto plazo de dos años desde que se produzcan los daños para los perjudicados, y dos años también para la acción de repetición contra los demás o los aseguradores contra ellos, desde la firmeza de la resolución judicial que condena al responsable a indemnizar por los daños, o a partir de la fecha en que se hubiera procedido a indemnizar de forma extrajudicial.

La brevedad del plazo $^{14}$ se agrava si tenemos en cuenta que de acuerdo con el artículo 6.5 el cómputo de los plazos de responsabilidad y garantía se iniciará a partir de la fecha en que se suscriba el acta de recepción ${ }^{15}$, con lo cual si el vicio se evidencia por ejemplo a

14 RodRíguez Achútegui (obra citada, pág. 31) subraya cómo, de forma inexplicada, el plazo se reduce de manera drástica salvo que los daños se deriven de elementos estructurales o cimentación y afecten a la resistencia mecánica y estabilidad del edificio. Y también MEZQUITA GARCÍA GRANERO (obra citada, pág. 44) subraya la «sustancial rebaja en los tiempos de prescripción de las acciones».

15 Para González Poveda («Responsabilidades y garantías» en Derecho de la Edificación coordinado por SALA SÁnchEZ, Barcelona 2000, pág. 287) el cómputo de los plazos se resume de la siguiente forma:

«a) desde la fecha del acta de recepción de la obra si no se han manifestado reservas en ellas; b) desde la fecha en que se entiendan subsanadas las reservas hechas en el acta de recepción o dentro de los treinta días siguientes a la terminación de la obra, acreditada en el certificado final de obra, plazo de treinta días que se contará a partir de la notificación por escrito al promotor, siempre que esas reservas o rechazo motivado por el promotor se hagan por escrito; c) desde la fecha de la aceptación tácita que se entiende produci- 
los cinco días de terminada la construcción y de efectuada la recepción de la obra, y el correspondiente inmueble - o de los pisos y locales que lo componen- no se vende hasta dos años y dos meses después de efectuada la recepción de la obra, nos encontraríamos con la paradoja de que los compradores de la casa no pueden ejercitar ninguna acción de garantía, porque habría prescrito, por muy graves que fueran los vicios o defectos y aun cuando afectarán a la estructura misma de la casa. Lo absurdo del precepto salta a la vista, además de su colisión con el artículo 1.969 Código Civil cuando determina que la prescripción de toda clase de acciones se contará desde el día en que pudieran ejercitarse, y no puede entenderse por tal el momento en que todavía no existían unos terceros perjudicados que pudieran reclamar $^{16}$.

\section{Seguro}

Tal vez la mayor novedad de la Ley es el seguro obligatorio de daños materiales y de caución que se prevé en tres modalidades, con arreglo al artículo 19.1, para garantizar los distintos daños que puedan ocasionarse durante la construcción:

«1. El régimen de garantías exigibles para las obras de edificación comprendidas en el artículo 2 de esta Ley se hará efectivo de acuerdo con la obligatoriedad que se establezca en aplicación de la disposición adicional segunda, teniendo como referente a las siguientes garantías:

a) Seguro de daños materiales o seguro de caución, para garantizar durante un año, el resarcimiento de los daños materiales por vicios o defectos de ejecución que afecten a elementos de terminación o acabado de las obras, que podrá ser sustituido por la retención por el promotor de un 5\% del importe de la ejecución material de la obra.

b) Seguro de daños materiales o seguro de caución, para garantizar durante tres años el resarcimiento de los daños causados por vicios o defectos de los elementos constructivos o de las instala-

da transcurridos treinta días desde la fecha de terminación de la obra, acreditada en el certificado final de obra y que se contará a partir de la fecha de notificación por escrito al promotor, si éste, dentro de ese plazo, no pone de manifiesto reservas o rechazo motivado por escrito».

${ }^{16}$ La jurisprudencia francesa ha tenido que interpretar de forma amplia el similar precepto contenido en el artículo 1.792.6 redactado por Ley de 4 de enero de 1978. Así Civ., 3. a 10 de enero de 1990, Bull. Civ. III n. ${ }^{\circ} 6$. 
ciones que ocasionen el incumplimiento de los requisitos de habitabilidad del apartado 1, letra c) del artículo 3.

c) Seguro de daños materiales o seguro de caución, para garantizar durante diez años, el resarcimiento de los daños materiales causados en el edificio por vicios o defectos que tengan su origen o afecten a la cimentación, los soportes, las vigas los forjados, los muros de carga u otros elementos estructurales, y que comprometan directamente la resistencia mecánica y estabilidad del edificio».

El seguro se prevé en tres modalidades conforme a las tres categorías de los daños que son origen de responsabilidad, de acuerdo con el artículo 17.1 y por los mismos plazos fijados en dicho artículo, es decir, de un año, tres y diez años.

Según el artículo 19.2 el tomador del seguro será el constructor en el supuesto a) y el promotor en los supuestos b) y c), y los asegurados, el propio promotor y los sucesivos adquirentes del edificio o de parte del mismo, debiendo estar la prima pagada en el momento de la recepción de la obra, y pudiéndose no obstante fraccionar, pero, en ese caso, el impago no da derecho al asegurador a resolver el contrato. Con tal dicción legal se prevé la obligatoriedad de la constitución del seguro durante todo el tiempo de la garantía legal, y sin que el impago de las primas o la desaparición jurídica de los agentes que intervienen en la edificación puedan alterar tales garantías.

Sin embargo hay unas importantes limitaciones a este teórico panorama de seguro obligatorio:

a) Como queda dicho de acuerdo con la disposición adicional segunda-uno sólo son exigibles a partir de la entrada en vigor de la Ley el seguro para los daños estructurales pero no de los demás daños comprendidos en los apartados a) y b) del artículo 19.1 .

b) Que no se extiende la garantía a los edificios no destinados a vivienda.

c) Que la garantía se extiende durante los diez años y en tal supuesto quedarían fuera del seguro los daños producidos dentro del período de garantía, pero reclamados ulteriomente sin que hubiera llegado todavía la prescripción de los mismos.

d) Otra curiosa precisión legal es la de que el seguro de daños materiales puede sustituirse por la retención de un 5\% del importe de la ejecución material de la obra. La Ley habla de la retención por el promotor pero, ¿dónde se retendrá por el promotor tal cantidad, o dónde la ingresará?: porque, evidentemente, que la suma retenida esté en poder del promotor — que luego puede re- 
sultar insolvente - no es ninguna garantía para los ulteriores adquirentes del inmueble.

El incumplimiento de las normas sobre garantía de suscripción obligatoria señalada en el número 7 del artículo 19 dará origen a la responsabilidad del obligado a suscribir las garantías; tal norma es confusa, porque el obligado a suscribir la garantía responde, también personalmente, si es el constructor o si es el promotor, de acuerdo con el artículo 17, por lo que la dicción legal podría tener tres posibles interpretaciones:

a) Que si se suscribe un seguro la responsabilidad es subsidiaria. Tal interpretación no tiene ningún sentido práctico, por lo que no parece deba sostenerse.

b) Que en el supuesto de no suscribir el seguro, el constructor o el promotor responde también de los vicios de los que fuera responsable el arquitecto $u$ otro agente que intervenga en el proceso edificatorio: esta interpretación no parece que pueda mantenerse ya que sería desproporcionada e iría en contra de un principio intrínseco de justicia.

c) Que en el caso de que no haya suscrito las garantías responde la persona física que no las ha suscrito y que fuera el representante legal de la empresa constructora o promotora además de ésta. Tal conclusión parece que deba de ser la preferida, aun cuando, forzoso es reconocerlo, tiene una interpretación extensiva del precepto legal que además de oscuro no señala específicamente tal responsabilidad personal en el supuesto de entes societarios.

El mayor realce e importancia que se le da a la necesidad del contrato de seguro viene dado por constituir requisito para la inscripción en el Registro de la Propiedad la declaración de obra nueva la constitución de las garantías que se prevén en el artículo 19, de acuerdo con el artículo 20 de la propia Ley.

También hay que tener en cuenta que la Ley prevé que el seguro es obligatorio para los agentes que intervienen en el proceso edificatorio, pero no señala lo mismo para las compañías de seguros, con lo cual podría suceder que no se encontrara una aseguradora que aceptara efectuar el correspondiente contrato y, en tal supuesto, todas las previsiones legales caerían por su base; aun cuando sea obligatorio el seguro para el desenvolvimiento del normal proceso edificatorio - y por eso precisamente- el mismo no quedaría cumplido y los pisos no podrían inscribirse en el Registro de la Propiedad, y todas las previsiones legales quedarían truncadas. 
Posiblemente en tal hipótesis, que podría ser más o menos peregrina, el legislador habilitaría medios para suplir esa situación, bien modificando la Ley, bien obligando a las compañías de seguros a suscribir los correspondientes contratos.

\section{Otras responsabilidades}

De acuerdo con el artículo 17.9:

«Las responsabilidades a que se refiere este artículo se entienden sin perjuicio de las que alcanzan al vendedor de los edificios o partes edificadas frente al comprador conforme al contrato de compra-venta suscrito entre ellos, a los artículos 1.484 y siguientes del Código Civil y demás legislación aplicable a la compra-venta».

Por tanto, de acuerdo con el texto mencionado, la Ley de Ordenación de la Edificación no excluye las acciones que se derivan del contrato de compraventa, a tenor de los artículos 1.484 y siguientes del Código Civil, pero el problema de tales acciones es su corto plazo de prescripción de seis meses, de acuerdo con el artículo 1.490, razón por la que precisamente el Tribunal Supremo había rechazado el encuadramiento dentro de estos artículos de la garantía decenal ${ }^{17}$.

Por eso llama la atención el que la nueva Ley se refiera a unos plazos notablemente más perentorios $-\mathrm{y}$ exclusivamente contra el vende-

17 Sentencias 10 de junio de 1983, Ar. 3.454; 21 de octubre de 1985, Ar. 4.959 y 25 de noviembre de 1988, Ar. 8.713. Esta última sentencia indica:

«Sin que merezcan mejor fortuna los que restan por examinar $-2 .^{\circ}$ y $5{ }^{\circ}-$ de los que integran la impugnación ejercitada por los demandados, en cuanto que tales motivos destinados a cuestionar, junto a temas ya examinados y claudicados, la infracción supuesta de los artículos 1.484 y 1.490 del Código Civil y la de la norma del $1.591 \mathrm{del}$ mismo, en orden a la naturaleza de los defectos y consiguiente prescripción de las acciones ejercitadas que el último de los motivos ahora en estudio - el 5. - - dice acaecida el 21 de enero de 1983, esto es varios meses antes de la fecha de presentación demanda que tuvo lugar el 27 de noviembre siguiente, no tienen en cuenta ni que la normativa de los artículos 1.484 y 1.490 del Código Civil, reguladora de las acciones redhibitoria y «quanti minoris», resultan inaplicables en aquellos supuestos, como el presente, en que la demanda se dirige a obtener las reparaciones derivadas del defectuoso cumplimiento de la obligación contractual por vicios cuya entidad los hace enmarcables en el ámbito del artículo 1.591 del propio Código, ni la permanente doctrina que señale ser uno el plazo de garantía y otro el de prescripción de la acción, de manera que no cabe sustituir por un plazo — el decenal— el de duración de la acción respecto de la que en el caso del párrafo $1 .^{\circ}$ del artículo 1.591, como en el supuesto de su inciso final, es el de 15 años como puntualiza entre tantas otras, la sentencia de 13 de julio 1987». 
dor de los edificios- de acuerdo al artículo 1.484 y siguientes del Código Civil; lo que sí había admitido la jurisprudencia antes de la Ley actual es la acción de cumplimiento contractual, basándose en los artículos 1.091, 1.098, 1.101 y 1.258 del Código Civil que tienen por base las normas generales sobre obligaciones, que deriva de una numerosa jurisprudencia la cual señala cómo el contrato no se encuentra cumplido mientras su ejecución sea defectuosa o viciosa; de ahí que cuando existan vicios en la edificación el contrato puede entenderse como no cumplido y así lo había manifestado el Tribunal Supremo ${ }^{18}$.

La diferencia fundamental de la acción de cumplimiento contractual con la acción del artículo 1.591 es que siendo el plazo de prescripción de la primera de ellas de quince años, no tenían que evidenciarse los vicios o defectos dentro de los diez años de garantía decenal, sino que bastaba con que se ejercitara la acción en el plazo de quince años. Aun cuando, eso sí, la acción debería ejercitarse en principio frente al contratista ${ }^{19}$.

¿Cabrá ejercitar tal acción de cumplimiento contractual? Entiendo que sí y ello por varios motivos:

a) No hay ninguna derogación expresa, es más, no se aceptó el dictamen de la ponencia del Congreso que proponía su derogación expresa.

b) La regulación de la acción de cumplimiento contractual y la de garantía decenal no se oponen ni son contradictorias y por eso no puede incluirse la acción de cumplimiento contractual en la cláusula derogatoria genérica de la nueva Ley. Es más, tal derogación crearía un sin número de problemas, porque en tal caso habría que pensar ¿en qué supuestos está derogada la acción de cumplimiento contractual y en cuáles no?; porque evidentemente en la Ley de Ordenación de la Edificación no se iban a derogar todas las posibles exigencias de cumplimiento contractual que nada tengan que ver con ésta.

18 Sentencia 13 de diciembre de 1983, Ar. 6.960; 22 de octubre de 1984, Ar. 4.409; 20 de septiembre de 1985, Ar. 4.281 y 24 de enero de 1990, Ar. 2.167.

19 Aun cuando algunas sentencias de la jurisprudencia menor han mantenido que se podía ejercitar también frente al arquitecto: así sentencias de 13 de noviembre de 1976, Ar. 4.775; A.T. Oviedo 13 de febrero de 1979, R.G.D. p. 110 de 1980; A.T. de Barcelona 23 de octubre de 1984, R.G.D. p. 565 de 1985 y A.T. de Madrid 3 de febrero de 1983, R.G.D. p. 831 de 1983. Incluso algún fallo del Tribunal Supremo ha entendido que en estos casos podría estimarse la responsabilidad solidaria de técnicos y constructores, así sentencia de 9 de marzo de 1989, Ar. 2.031. 
c) En cualquier caso la acción de cumplimiento contractual puede ejercitarse como acción derivada de la compraventa y en tal sentido puede entenderse dentro de la referencia del artículo 17.9, a que las garantías no cubrirán «salvo pacto en contrario», y a la expresión «sin perjuicio de sus responsabilidades contractuales» del artículo $17.1^{20}$.

Otras acciones que deben entenderse subsistentes son las de los artículos 1.907 y 1.909 del Código Civil, exigibles frente a los responsables por imperativo de dichos artículos en relación al 1.591, todos ellos del Código Civil.

Notemos además que las responsabilidades que se derivan del artículo 17 afectan todas ellas a la nueva construcción y no a las colindantes; y que el seguro previsto lo es en relación con esos mismos daños, por lo que de ninguna manera se aseguran los daños a las edificaciones colindantes tan frecuentes cuando la nueva construcción está emplazada entre otras antiguas.

También es evidente que las acciones penales por un posible delito seguirán existiendo; y, lógicamente, también las acciones de responsabilidad administrativa cuando se trate de viviendas de protección oficial.

Lo que es más problemático es si el artículo 1.591 del Código Civil ha sido o no derogado por la nueva regulación, aun cuando a primera vista parecería que existe una derogación evidente.

La disposición derogatoria señala, con fórmula usual, que quedan derogadas las disposiciones de rango igual o inferior a ésta que se opongan a lo dispuesto en esta Ley, con lo cual parecería lógico pensar que el artículo 1.591 está derogado.

Esta interpretación se reforzaría con la exposición de motivos, puesto que en la misma se indica que se trata de dar una nueva regulación legal a la edificación, y el mantenimiento de dos regulaciones diferentes es contradictorio y debe presuponerse que la nueva ha derogado a la vieja, en virtud de la disposición derogatoria de la Ley; pero no obstante a lo anterior, hay que observar que las garantías previstas en la Ley lo son solamente para los supuestos de viviendas de acuerdo con la disposición adicional segunda que señala:

«Uno. La garantía contra los daños materiales a que se refiere el apartado 1.c) del artículo 19 de esta Ley será exigible, a partir de su entrada en vigor, para edificios cuyo destino principal sea el de vivienda.

20 Así lo reconoce MezQuita García Granero (obra citada, pág. 35). 
Dos. Mediante Real Decreto podrá establecerse la obligatoriedad de suscribir las garantías previstas en los apartados 1.a) y 1.b) del citado artículo 19, para edificios cuyo destino principal sea el de vivienda. Asimismo, mediante Real Decreto podrá establecerse la obligatoriedad de suscribir cualesquiera de las garantías previstas en el artículo 19, para edificios destinados a cualquier uso distinto del de vivienda».

CORDERo LoBATO ${ }^{21}$ estima que el artículo 1.591 sí ha sido derogado, por una serie de razones que expone, por la LOE aunque añade que ésta debe regular toda la materia que estaba contenida en aquél y recogerla en sus artículos 17 y 18. También RodRígueZ ACHÚteGuI ${ }^{22}$ recoge el interrogante que plantea la falta de derogación expresa del artículo 1.591 del Código Civil, pero se muestra partidario de su derogación por la nueva Ley, lo mismo que GonzÁlez PÉrez ${ }^{23}$ y GonzÁlez PovedA ${ }^{24}$. En cambio Almagro Nosete ${ }^{25}$ estima que el artículo 1.591 del Código Civil sigue vigente, aun cuando se haya reducido su ámbito de aplicación de modo notable, entendiendo que:

«a) Las obras de edificación de nueva construcción de "escasa entidad constructiva y sencillez técnica que no tenga, de forma eventual o permanente, carácter residencial, ni público y se desarrollen en una sola planta" están exluidas del ámbito de aplicación de la ley especial por disposición expresa (artículo 2.2.a)) pero no de su sujeción general al artículo 1.591 del Código Civil.

b) La extensión de la responsabilidad figura limitada por el artículo 17 de la LOE, a los daños materiales por lo que se suscitan dudas fundadas acerca de si de tal concepto están excluidos los daños "corporales" y más acusadamente los perjuicios y los daños morales, lo que conduciría a que estos últimos desaparezcan como conceptos indemnizables en situaciones de "ruina", o encuentren acogida — como parece más razonable - al amparo de la expresión "daños y perjuicios" que recoge el artículo 1.591 del Código Civil, por lo que, en definitiva éste permanece vigente respecto de estos supuestos.

c) De antiguo ha sido objeto de controversia entre los civilistas, la naturaleza de la responsabilidad derivada del artículo 1.591 del Código Civil si contractual o extracontractual. La LOE parece inclinarse por el carácter de obligación legal extracontractual, al referirse en el inciso

21 «Comentario al artículo 17 LOE» en Comentarios a la Ley de Ordenación de la Edificación, citado, pág. 347.

22 Obra citada, págs. 35 y sigs.

23 Obra citada, pág. 579.

24 «Comentario del Código Civil» citado, tomo 7, pág. 629.

25 «Algunas cuestiones procesales» en Derecho de la Edificación coordinado por SALA SÁNCHEZ, citado, pág. 375. 
inicial del artículo 17 a las responsabilidades contractuales que deja a salvo o fuera del contenido de la responsabilidad que regula. De aquí, asimismo que puedan originarse dudas sobre el alcance del último párrafo del artículo 1.591 claramente ubicado en las responsabilidades contractuales».

Y Almagro Nosete concluye señalando que los problemas derivados de la coordinación del artículo 1.591 del Código Civil y los preceptos de la LOE originarán probablemente en el futuro cuestiones litigiosas que tendrán que despejar la jurisprudencia.

Si las garantías son solamente para viviendas y la garantía es un medio fundamental de la nueva Ley, que debe contemplarse como un todo armónico que por una parte disminuye los plazos, pero por otra adopta una serie de garantías, podría propugnarse que en aquellos casos en que la garantía no existe puede seguir siendo aplicable y exigible el artículo 1.591, y en ese supuesto nos encontraríamos los edificios no destinados a vivienda en los que no se exigen las garantías de seguro, de acuerdo con la disposición adicional segunda de la Ley; de la misma forma que en algunos ordenamientos jurídicos — como el francés o el suizo - la garantía decenal específica sigue conviviendo con la responsabilidad normal del derecho común basada en la culpa extracontractual.

Las anteriores conclusiones se refuerzan si tenemos en cuenta que la garantía legal es solamente para los vicios estructurales, que mientras no se acuerde por un nuevo Real Decreto el seguro no se extenderá a los vicios garantizados por períodos anual y trianual.

Por supuesto la nueva Ley no excluye la posibilidad de que existieran, además de las civiles, responsabilidades administrativas, penales o laborales ${ }^{26}$.

\section{Subrogación}

La disposición adicional séptima indica:

«Quien resulte demandado por ejercitarse contra él, acciones de responsabilidad basadas en las obligaciones resultantes de su intervención en el proceso de la edificación previstas en la presente Ley, podrá solicitar, dentro del plazo que la Ley de Enjuiciamiento Civil concede para contestar a la demanda, que ésta se notifique a otro u otros agentes que también hayan tenido intervención en el referido proceso.

26 RodríGUeZ ACHÚTEGUI, obra citada, pág. 28. 
La notificación se hará conforme a lo establecido para el emplazamiento de los demandados e incluirá la advertencia expresa a aquellos otros agentes llamados al proceso de que, en el supuesto de que no compareciesen, la sentencia que se dicte será oponible y ejecutable frente a ellos».

Tal disposición adicional presenta una serie de problemas ya que de esta forma un procedimiento contra una sola persona puede convertirse en un procedimiento contra varias, con el mayor tiempo que ello conlleva y además con un incremento notable de los gastos. ¿Y qué sucederá si hay condena en costas? ¿A quiénes se les condena?: no parece lógico ni justo, ni viable legalmente que el demandante sea condenado, en aplicación del contenido del artículo 523 de la Ley de Enjuiciamiento Civil al pago de las costas de personas que él no ha traído a la litis. Por eso el hacerlo respecto a quien pida la llamada en garantía también es problemático, puesto que en la Ley no está prevista esta posibilidad: la realidad es que este precepto, como otros de la nueva Ley, crean una serie de interrogantes debido fundamentalmente a su poca claridad y falta de tecnicismo.

\section{Conclusiones}

Las conclusiones que se observan de un somero repaso de la Ley en cuanto al régimen de responsabilidad civil son las siguientes:

Primera. La Ley introduce una inseguridad jurídica cuando alude a unos criterios de habitabilidad imprecisos, borrosos y difuminados.

Segunda. La Ley acorta sustancialmente los plazos de garantía y lo que es más grave, los de prescripción, (que ciertamente antes eran demasiado largos) hasta el extremo de que si se sigue la literalidad del precepto, se podían entender prescritas las acciones de aquellos compradores que hubieran comprado después de dos años y un día de la recepción de la obra sin que los promotores hubieran antes ejercitado ninguna acción.

Tercera. Con la nueva Ley se favorece claramente a los técnicos - arquitectos y aparejadores- mientras que salen perjudicados los promotores y constructores.

Cuarta. No se prevé una normativa para la responsabilidad por daños a las edificaciones colindantes.

Quinta. El seguro se limita hasta que por Real Decreto se amplíe la garantía a los supuestos de daños a la estructura del edificio que previene el artículo 19.1.a), omitiendo por ahora las otras categorías de daños, de prescripción anual o trianual. 
Sexta. Debe entenderse que continúa vigente la acción de garantía contractual además de la de los daños a los colindantes contenida en los artículos 1.907 y 1.909 del Código Civil; y puede mantenerse fundadamente la continuación de la vigencia — al menos puntual— del artículo 1.591 Código Civil.

Séptima. Se prevé una especie de llamada en garantía procesal no exenta de complicaciones

Octava. Se ligan los derechos y obligaciones de las partes con un código técnico de la edificación, el cual no existe.

En conclusión además de crear la incógnita de su aplicación, la nueva Ley de Ordenación de la Edificación ofrece unas importantes lagunas y un tratamiento legal que en algunos casos no mejora, sino todo lo contrario, la regulación actual contenida en el artículo 1.591 del Código Civil, tal y como ha sido interpretado por la jurisprudencia del Tribunal Supremo.

\section{Bibliografía}

\section{Posteriores a la Ley}

Carrasco Pereda, (coordinador) Comentarios a la Ley de Ordenación de la Edificación, Pamplona 2000, p. 343.

GonZÁLEZ PÉREZ, Comentarios a la Ley de Ordenación de la Edificación, Madrid, 2000, pp. 364.

MezQuita GarCÍA GRANERo, «El artículo 1.591 C.C. ante la Ley de ordenación de la edificación», en Aranzadi Civil, 1999,-III, pp. 2.301 y ss.

RodríGUeZ ACHÚtegui, «Ley de Ordenación de la Edificación: Responsabilidades, Garantías y Asesoramiento» en Revista del Ilustre Colegio de Abogados del Señorío de Vizcaya, Enero-Marzo 1999, pp. 25 y ss.

SAla SÁnCHEZ, (coordinador) Derecho de la Edificación, Barcelona, 2000, p. 375.

Sierra Gil de la Cueva, (coordinador) Comentarios al Código Civil, t. 7, Barcelona, 2000.

\section{Anteriores a la Ley}

CADARSo PALAU, La responsabilidad decenal de arquitectos y constructores, Madrid, 1976.

Del ARCo y Pons, Derecho de la construcción, Madrid, 1980.

FERnÁNDEZ COSTALES, El contrato de arquitecto en edificación, Madrid, 1977.

FERNÁNDEZ HIERRo, La responsabilidad civil por vicios de construcción, Bilbao, 1976.

—, «Responsabilidad profesional, falta de tratamiento unívoco» en Estudios de Deusto, vol. 45/2, pp. 163 y ss. 
—, «La Responsabilidad en la construcción según la jurisprudencia civil», en Poder Judicial n. ${ }^{\circ}$ VII, p. 282.

GARCÍA CANTERO, «La responsabilidad por ruina de los edificios en el artículo 1.591 del Código Civil» en ADC 1963, p. 1.105.

GÓMEZ DE LA ESCALERA, La responsabilidad civil de los promotores, constructores y técnicos por los defectos de construcción (Estudio del artículo $1.591 \mathrm{del}$ Código Civil y su problemática actual), Barcelona, 1990.

Herrera Catena, La responsabilidad en la construcción, Granada, 1977, pp. 124 y ss.

HuET, Responsabilité contractuelle et responsabilité délictuelle. Essai de délimitation entre les deux ordres de responsabilité, Paris, 1978.

LEROY, Contribution à l'étude des obligations du professionnel (les devoirs de répondre des risques crées par l'activité et le devoir de maîtrise professionnelle), Toulouse, 1995.

MARTínez CAlCERRADA, La responsabilidad civil profesional, Madrid, 1996.

Mucius Scaevola, Código Civil, Madrid, 1915.

RUBIO SAN RomÁn, La responsabilidad civil en la construcción, Madrid, 1987.

SÁNCHEZ CALERO, El contrato de obra, su cumplimiento, Madrid, 1978.

SANTOS BRIZ, La responsabilidad civil, Madrid, 1970.

TRAVIESES, «Contrato de arrendamiento» en Revista de Derecho Privado, 1991, pp. 34 y ss.

YzQuiERdo Tolsada, La responsabilidad civil del profesional liberal, Madrid, 1989.

Zorrilla RuIZ, en Derecho Civil de Carbonnier, Barcelona, 1971. 